\title{
Effect of reaction conditions on the thermal stability of polystyrene grafted oil palm empty fruit bunch (OPEFB) fiber
}

\begin{abstract}
Polystyrene was grafted onto oil palm empty fruit bunch (OPEFB) fiber in aqueous medium by using the $\mathrm{H} 2 \mathrm{O} 2 / \mathrm{Fe} 2+$ system as an initiator. Optimization of the reaction conditions was carried out by varying the reaction period, temperature, amounts of the monomer, initiator and co-catalyst. The presence of the peaks around $3026 \mathrm{~cm}-1,698 \mathrm{~cm}-1$ and $755 \mathrm{~cm}-1$ in the Fourier transform infrared (FTIR) spectra of the grafted product and the presence of polystyrene on the surface of grafted OPEFB in the scanning electron micrograph provided strong evidence of the grafting. The maximum percentage of grafting (about 200\%) was achieved when the reaction was carried on for $4 \mathrm{~h}$ at a temperature of $65^{\circ} \mathrm{C}$, using 52.27 mmol monomer, $6.00 \mathrm{mmol}$ initiator and $0.26 \mathrm{mmol}$ co-catalyst. The thermal stability of the grafted OPEFB was found to be better than that of the ungrafted fiber, as seen from thermogravimetric analysis (TGA).
\end{abstract}

Keyword: Fiber; Grafting; Oil palm empty fruit bunch; Polystyrene; Reaction condition 